\title{
APPLICATION OF A NEW CLASS CUMULATIVE LIFETIME DISTRIBUTION TO SOFTWARE RELIABILITY ANALYSIS
}

\author{
NIKOLAY PAVLOV ${ }^{1}$, ANTON ILIEV ${ }^{2}$, \\ ASEN RAHNEV ${ }^{3}$, AND NIKOLAY KYURKCHIEV ${ }^{4}$ \\ 1,2,3,4 Faculty of Mathematics and Informatics \\ University of Plovdiv Paisii Hilendarski \\ 24, Tzar Asen Str., 4000 Plovdiv, BULGARIA
}

ABSTRACT: In this paper we consider the application of a a new class of cumulative distribution function proposed by Ramos, Dey, Louzada and Lachos in [9] to the debugging theory.

We study the Hausdorff approximation of the shifted Heaviside step function by this family.

Numerical examples, illustrating our results are presented using programming environment Mathematica.

We give also real examples with data provided in [30] using the new software reliability model. Dataset included [31] Year 2000 compatibility modifications, operating system upgrade, and signaling message processing.

AMS Subject Classification: 68N30, 41A46

Key Words: extended Poisson-exponential cumulative distribution function (EPcdf), Heaviside function, Hausdorff approximation, upper and lower bounds

Received: February 12, 2018; Accepted: August 5, 2018;

Published: September 11, 2018. doi: 10.12732/caa.v22i4.4

Dynamic Publishers, Inc., Acad. Publishers, Ltd. http://www.acadsol.eu/caa 


\section{INTRODUCTION}

Some extensions of the well-known Poisson, Poisson-exponential, Chen, Exponentiated Chen, modified Weibull and Burr distributions can be found in: [1]-[8].

Some software reliability models, can be found in [10]-[28].

Another model that uses the "Gompertz-type correction" is the extended Poisson-exponential cumulative distribution function (EPcdf). The (EPcdf) is given by (see for instance [9]):

$$
M(t ; \lambda ; \theta)=\frac{e^{\lambda \frac{1-e^{-\theta t}}{1-e^{-\theta}}}-1}{e^{\lambda}-1}
$$

where $\theta>0 ; \lambda>0$.

We consider the following class of this family with application to the population dynamics and debugging theory:

$$
M_{1}(t)=\frac{e^{\lambda \frac{1-e^{-\theta t}}{1-e^{-\theta}}}-1}{e^{\lambda}-1}
$$

with

$$
t_{0}=-\frac{1}{\theta} \ln \left(1-\frac{1-e^{-\theta}}{\lambda} \ln \left(\frac{1+e^{\lambda}}{2}\right)\right) ; \quad M_{1}\left(t_{0}\right)=\frac{1}{2} .
$$

In this note we study the Hausdorff approximation of the shifted Heaviside step function

$$
h_{t_{0}}(t)=\left\{\begin{array}{ccc}
0, & \text { if } & t<t_{0} \\
{[0,1],} & \text { if } \quad t=t_{0} \\
1, & \text { if } \quad t>t_{0}
\end{array}\right.
$$

by this family.

Definition 1. [29] The Hausdorff distance (the H-distance) $\rho(f, g)$ between two interval functions $f, g$ on $\Omega \subseteq \mathbb{R}$, is the distance between their completed graphs $F(f)$ and $F(g)$ considered as closed subsets of $\Omega \times \mathbb{R}$. More precisely,

$$
\rho(f, g)=\max \left\{\sup _{A \in F(f)} \inf _{B \in F(g)}\|A-B\|, \sup _{B \in F(g)} \inf _{A \in F(f)}\|A-B\|\right\},
$$

wherein $\|$.$\| is any norm in \mathbb{R}^{2}$, e. g. the maximum norm $\|(t, x)\|=\max \{|t|,|x|\}$; hence the distance between the points $A=\left(t_{A}, x_{A}\right), B=\left(t_{B}, x_{B}\right)$ in $\mathbb{R}^{2}$ is $\|A-B\|=\max \left(\left|t_{A}-t_{B}\right|,\left|x_{A}-x_{B}\right|\right)$. 
We propose a software modules (intellectual properties) within the programming environment CAS Mathematica for the analysis. The models have been tested with real-world data.

\section{MAIN RESULTS}

The one-sided Hausdorff distance $d$ between the function $\left.h_{t_{0}}(t)\right)$ and the function - ((2)-(3)) satisfies the relation

$$
M_{1}\left(t_{0}+d\right)=1-d
$$

The following theorem gives upper and lower bounds for $d$

Theorem 1. Let

$$
\begin{gathered}
p=-\frac{1}{2} \\
q=1+\frac{\theta \lambda\left(1+e^{\lambda}\right)}{2\left(1-e^{-\theta}\right)\left(e^{\lambda}-1\right)}\left(1-\frac{1-e^{-\theta}}{\lambda} \ln \frac{1+e^{\lambda}}{2}\right), \\
r=2.1 q
\end{gathered}
$$

For the one-sided Hausdorff distance $d$ between $\left.h_{t_{0}}(t)\right)$ and the function $((2)-$ (3)) the following inequalities hold for: $q>\frac{e^{1.05}}{2.1}$

$$
d_{l}=\frac{1}{r}<d<\frac{\ln r}{r}=d_{r} .
$$

Proof. Let us examine the function:

$$
F(d)=M_{1}\left(t_{0}+d\right)-1+d
$$

From $F^{\prime}(d)>0$ we conclude that function $F$ is increasing.

Consider the function

$$
G(d)=p+q d
$$

From Taylor expansion we obtain $G(d)-F(d)=O\left(d^{2}\right)$.

Hence $G(d)$ approximates $F(d)$ with $d \rightarrow 0$ as $O\left(d^{2}\right)$ (see Fig. 1).

In addition $G^{\prime}(d)>0$.

Further, for $q>\frac{e^{1.05}}{2.1}$ we have $G\left(d_{l}\right)<0$ and $G\left(d_{r}\right)>0$.

This completes the proof of the theorem. 


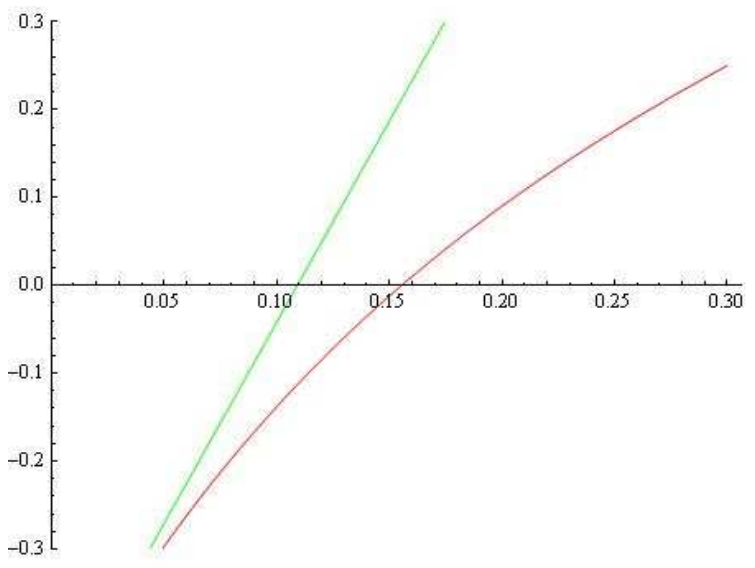

Figure 1: The functions $F(d)$ and $G(d)$ for $\theta=8 ; \lambda=0.5$.

The model $((2)-(3))$ for $\theta=8, \lambda=0.5, t_{0}=0.103098$ is visualized on Fig. 2. From the nonlinear equation (4) and inequalities (5) we have: $d=0.155378$, $d_{l}=0.103958, d_{r}=0.235337$.

The model $((2)-(3))$ for $\beta=15, \lambda=0.01, t_{0}=0.0463767$ is visualized on Fig. 3. From the nonlinear equation (4) and inequalities (5) we have: $d=0.104496, d_{l}=0.0561458, d_{r}=0.161689$.

The model $((2)-(3))$ for $\beta=25, \lambda=0.005, t_{0}=0.0277759$ is visualized on Fig. 4. From the nonlinear equation (4) and inequalities (5) we have: $d=0.0756055, d_{l}=0.0353142, d_{r}=0.118072$.

From the above examples, it can be seen that the proven estimates (see Theorem 1) for the value of the Hausdorff approximation is reliable when assessing the important characteristic - "saturation".

This characteristic (as we have already shown in our previous publications) has its equal participation together with the other two characteristics - "confidence intervals" and "confidence bounds" in the area of the Software Reliability Theory.

We propose a software module (intellectual properties) within the programming environment $C A S$ Mathematica for the analysis of the considered family $M_{1}(t)$.

The module offers the following possibilities:

- generation of the function under user defined values of the parameters $\lambda$, 


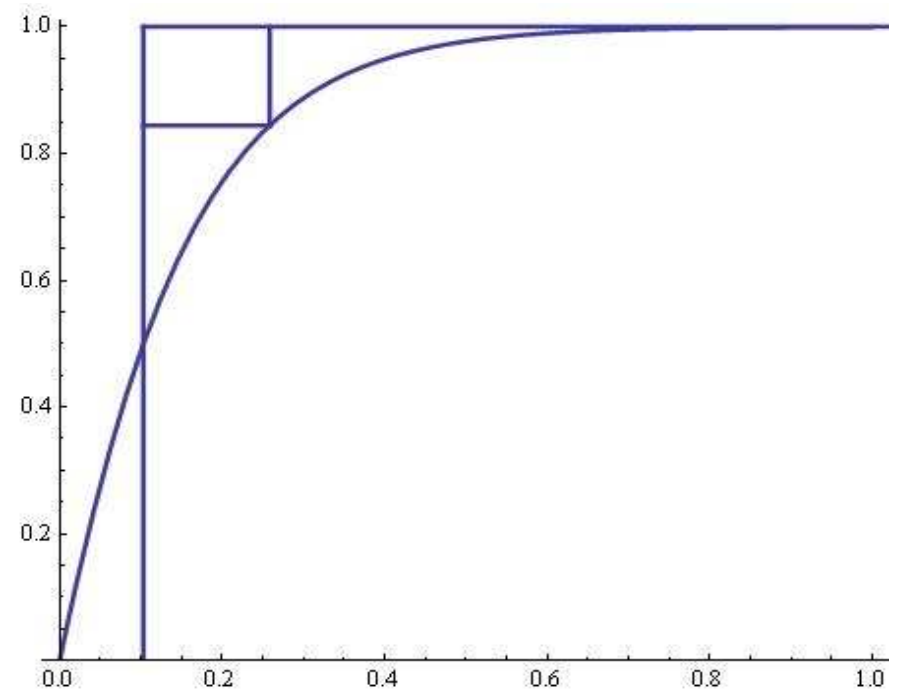

Figure 2: The model $((2)-(3))$ for $\theta=8, \lambda=0.5, t_{0}=0.103098$; $\mathrm{H}$-distance $d=0.155378, d_{l}=0.103958, d_{r}=0.235337$.

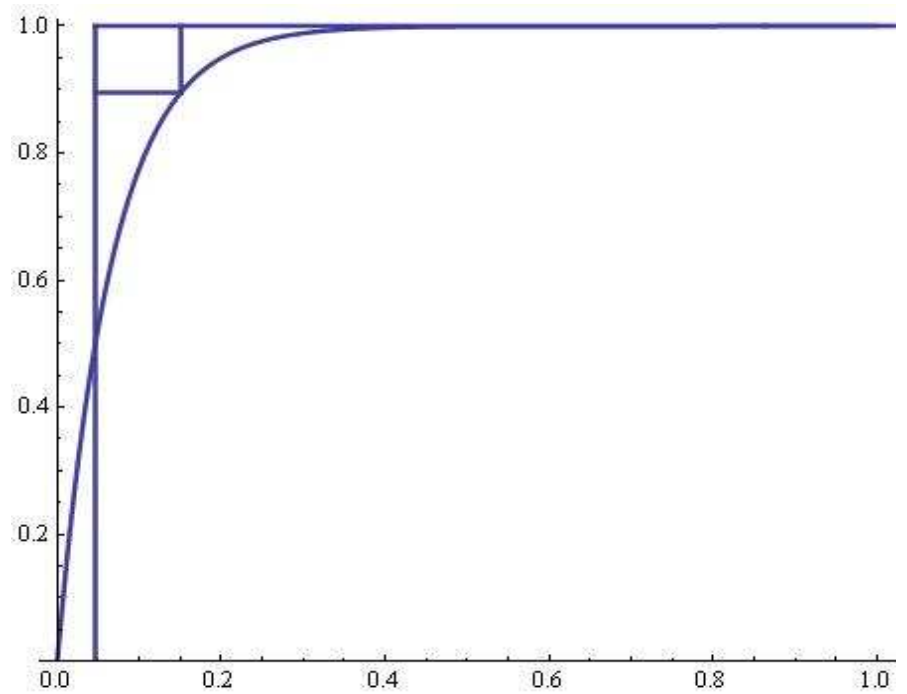

Figure 3: The model $((2)-(3))$ for $\beta=15, \lambda=0.01, t_{0}=0.0463767$; $\mathrm{H}$-distance $d=0.104496, d_{l}=0.0561458, d_{r}=0.161689$. 


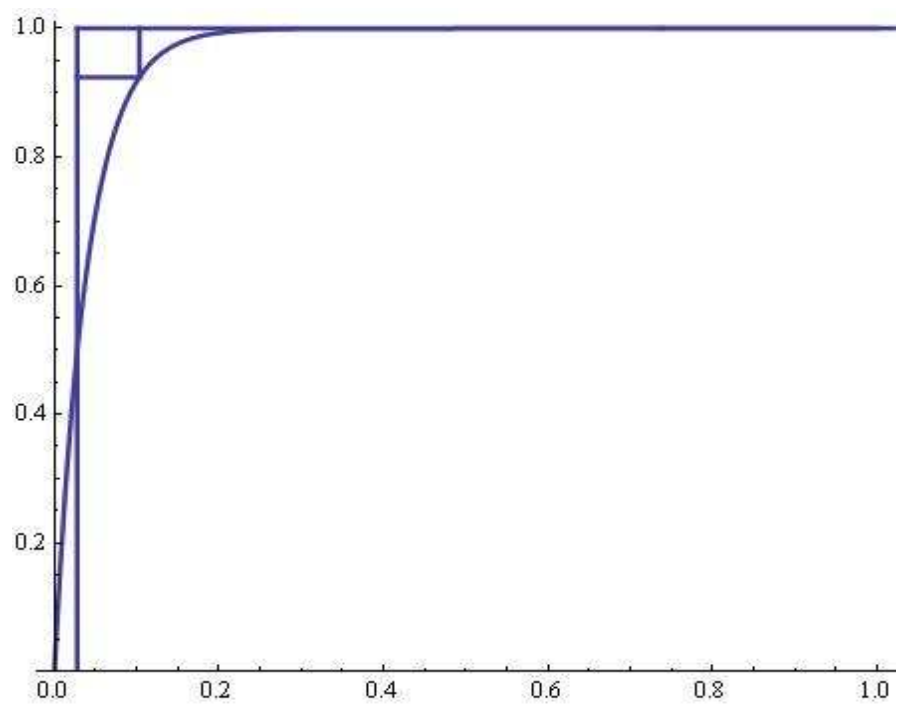

Figure 4: The model $((2)-(3))$ for $\beta=25, \lambda=0.005, t_{0}=0.0277759$; $\mathrm{H}$-distance $d=0.0756055, d_{l}=0.0353142, d_{r}=0.118072$.

and $\theta$;

- calculation of the H-distance $d$ between the function $\left.h_{t_{0}}(t)\right)$ and the function $M_{1}(t)$;

- software tools for animation and visualization.

\subsection{APPLICATION IN THE FIELD OF DEBUGGING AND TEST THEORY}

We give real examples with data provided in [30].

The operating time of the software is 167,900 days. 115 failures are detected for these days which contain 71 unique failures.

Table 1 shows the failures data which are united for each of the 13 months.

Dataset included [31] Year 2000 compatibility modifications, operating system upgrade, and signaling message processing. 


\begin{tabular}{|l|l|l|l|l|}
\hline $\begin{array}{l}\text { Month In- } \\
\text { dex }\end{array}$ & $\begin{array}{l}\text { System Days } \\
\text { (Days) }\end{array}$ & $\begin{array}{l}\text { System Days } \\
\text { (Cumulative) }\end{array}$ & Failures & $\begin{array}{l}\text { Cumulative } \\
\text { Failures }\end{array}$ \\
\hline 1 & 961 & 961 & 7 & 7 \\
\hline 2 & 4170 & 5131 & 3 & 10 \\
\hline 3 & 8789 & 13,920 & 14 & 24 \\
\hline 4 & 11,858 & 25,778 & 8 & 32 \\
\hline 5 & 13,110 & 38,888 & 11 & 43 \\
\hline 6 & 14,198 & 53,086 & 8 & 51 \\
\hline 7 & 14,265 & 67,351 & 7 & 58 \\
\hline 8 & 15,175 & 82,526 & 19 & 77 \\
\hline 9 & 15,376 & 97,902 & 17 & 94 \\
\hline 10 & 15,704 & 113,606 & 6 & 100 \\
\hline 11 & 18,182 & 131,788 & 11 & 111 \\
\hline 12 & 17,760 & 149,548 & 4 & 115 \\
\hline 13 & 18,352 & 167,900 & 0 & 115 \\
\hline
\end{tabular}

Table 1. Field failure data [30].

The fitted model

$$
M_{1}(t)=\omega \frac{e^{\lambda \frac{1-e^{-\theta t}}{1-e^{-\theta}}}-1}{e^{\lambda}-1}
$$

based on the data of Table 1 for the estimated parameters:

$$
\omega=7 ; \quad \theta=0.142302 ; \quad \lambda=0.317432
$$

is plotted on Fig. 5 .

We hope that the results will be useful for specialists in this scientific area.

\section{ACKNOWLEDGMENTS}

This work has been supported by the project FP17-FMI-008 of Department for Scientific Research, Paisii Hilendarski University of Plovdiv. 


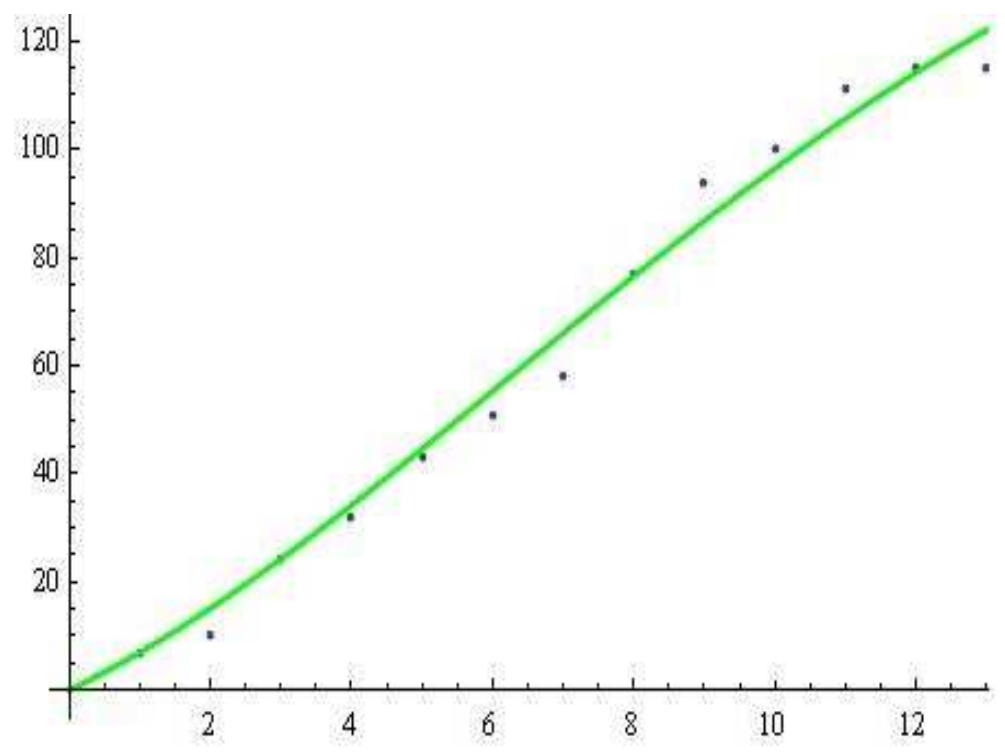

Figure 5: The fitted model $M_{1}(t)$.

\section{REFERENCES}

[1] Z. Chen, A new two-parameter lifetime distribution with bathtub shape or increasing failure rate function, Stat. and Prob. Letters, 49 (2000), $155-161$.

[2] M. Xie, Y. Tang, T. Goh, A modified Weibull extension with bathtubshaped failure rate function, Reliability Eng. and System Safety, 76 (2002), 279-285.

[3] M. Khan, A. Sharma, Generalized order statistics from Chen distribution and its characterization, J. of Stat. Appl. and Prob., 5 (2016), 123-128.

[4] S. Dey, D. Kumar, P. Ramos, F. Louzada, Exponentiated Chen distribution: Properties and Estimations, Comm. in Stat.-Simulation and Computation, (2017), 1-22.

[5] Y. Chaubey, R. Zhang, An extension of Chen's family of survival distributions with bathtub shape or increasing hazard rate function, Comm. in Stat.-Theory and Methods, 44 (2015), 4049-4069. 
[6] V. Cancho, F. Louzada, G. Barriga, The Poisson-exsponential lifetime distribution, Comp. Stat. Data Anal., 55 (2011), 677-686.

[7] G. Rodrigues, F. Louzada, P. Ramos, Poisson-exponential distribution: different methods of estimation, J. of Appl. Stat., 45, No. 1 (2018), 128144.

[8] F. Louzada, P. Ramos, P. Ferreira, Exponential-Poisson distribution: estimation and applications to rainfall and aircraft data with zero occurrence, Communication in Statistics-Simulation and Computation, (2018).

[9] P. Ramos, D. Dey, F. Louzada, V. Lachos, An extended Poisson family of lifetime distribution: A unified approach in competitive and Complementary risk, arXiv: submit/2267507 [stat.AP] 19 May 2018.

[10] N. Pavlov, A. Iliev, A. Rahnev, N. Kyurkchiev, Some software reliability models: Approximation and modeling aspects, LAP LAMBERT Academic Publishing (2018), ISBN: 978-613-9-82805-0.

[11] N. Pavlov, A. Iliev, A. Rahnev, N. Kyurkchiev, Nontrivial Models in Debugging Theory (Part 2), LAP LAMBERT Academic Publishing (2018), ISBN: 978-613-9-87794-2.

[12] N. Pavlov, A. Iliev, A. Rahnev, N. Kyurkchiev, On the extended Chen's and Pham's software reliability models. Some applications, Int. J. of Pure and Appl. Math., 118, No. 4 (2018), 1053-1067.

[13] N. Pavlov, G. Spasov, A. Rahnev, N. Kyurkchiev, A new class of Gompertz-type software reliability models, International Electronic Journal of Pure and Applied Mathematics, 12, No. 1 (2018), 43-57.

[14] N. Pavlov, G. Spasov, A. Rahnev, N. Kyurkchiev, Some deterministic reliability growth curves for software error detection: Approximation and modeling aspects, International Journal of Pure and Applied Mathematics, 118, No. 3 (2018), 599-611.

[15] N. Pavlov, A. Golev, A. Rahnev, N. Kyurkchiev, A note on the Yamadaexponential software reliability model, International Journal of Pure and Applied Mathematics, 118, No. 4 (2018), 871-882. 
[16] N. Pavlov, A. Iliev, A. Rahnev, N. Kyurkchiev, A Note on The "Mean Value" Software Reliability Model, International Journal of Pure and Applied Mathematics, 118, No. 4 (2018), 949-956.

[17] N. Pavlov, A. Golev, A. Rahnev, N. Kyurkchiev, A note on the generalized inverted exponential software reliability model, International Journal of Advanced Research in Computer and Communication Engineering, 7, No. 3 (2018), 484-487.

[18] N. Pavlov, A. Iliev, A. Rahnev, N. Kyurkchiev, Transmuted inverse exponential software reliability model, Int. J. of Latest Research in Engineering and Technology, 4, No. 5 (2018), 1-6.

[19] N. Pavlov, A. Iliev, A. Rahnev, N. Kyurkchiev, Analysis of the Chen's and Pham's Software Reliability Models, Cybernetics and Information Technologies, 18, No. 3 (2018), 37-47.

[20] N. Pavlov, A. Iliev, A. Rahnev, N. Kyurkchiev, On Some Nonstandard Software Reliability Models, Dynamic Systems and Applications, 27, No. 4 (2018), 757-771.

[21] N. Pavlov, A. Iliev, A. Rahnev, N. Kyurkchiev, Some deterministic growth curves with applications to software reliability analysis, Int. J. of Pure and Appl. Math., 119, No. 2 (2018), 357-368.

[22] N. Pavlov, A. Iliev, A. Rahnev, N. Kyurkchiev, Investigations of the Kstage Erlangian software reliability growth model, Int. J. of Pure and Appl. Math., 119, No. 3 (2018), 441-449.

[23] N. Pavlov, A. Iliev, A. Rahnev, N. Kyurkchiev, Some Transmuted Software Reliability Models, Journal of Mathematical Sciences and Modelling, 1, No. 2 (2018). (to appear)

[24] N. Pavlov, A. Iliev, A. Rahnev, N. Kyurkchiev, A Note on Ohbas Inflexion S-shaped Software Reliability Growth Model, Collection of scientific works from conference Mathematics. Informatics. Information Technologies. Application in Education, Pamporovo, Bulgaria, October 10-12, 2018. (to appear) 
[25] V. Kyurkchiev, A. Malinova, O. Rahneva, P. Kyurkchiev, On the Burr XII-Weibull Software Reliability Model, Int. J. of Pure and Appl. Math., 119, No. 4 (2018), 639-650.

[26] V. Kyurkchiev, A. Malinova, O. Rahneva, P. Kyurkchiev, Some Notes on the Extended Burr XII Software Reliability Model, Int. J. of Pure and Appl. Math., 120, No. 1 (2018), 127-136.

[27] S. Markov, N. Kyurkchiev, A. Iliev, A. Rahnev, A note on the Loglogistic and transmuted Log-logistic Models. Some applications, Dynamic Systems and Applications, 27, No. 3 (2018), 593-607.

[28] N. Kyurkchiev, A. Iliev, Extension of Gompertz-type Equation in Modern Science: 240 Anniversary of the birth of B. Gompertz, LAP LAMBERT Academic Publishing (2018), ISBN: 978-613-9-90569-0.

[29] F. Hausdorff, Set Theory (2 ed.) (Chelsea Publ., New York, (1962 [1957]) (Republished by AMS-Chelsea 2005), ISBN: 978-0-821-83835-8.

[30] D. R. Jeske, X. Zhang, Some successful approaches to software reliability modeling in industry, J. Syst. Softw., 74 (2005), 85-99.

[31] K. Song, H. Pham, A Software Reliability Model with a Weibull Fault Detection Rate Function Subject to Operating Environments, Appl. Sci., 7 (2017), 16 pp., doi:10.3390/app7100983 
